\title{
Causal agents of dieback of clematis (Clematis L.) leaves
}

\section{Przyczyny zamierania liści powojnika (Clematis L.)}

\author{
Maria Kowalik, Klaudia Duda
}

\section{Summary}

Dying clematis leaves were observed during a two-year study (2011-2012) conducted in the city of Krakow, Poland. The dying leaves showing symptoms of necrosis contained 46 fungi species. Alternaria alternata and Epicoccum nigrum dominated in the clematis phyllosphere. Arthinium phaeospermum, Boeremia exigua, Botrytis cinerea, Chaetomium globosum, Cladosporium cladosporioides, Fusarium oxysporum, Gibberella baccata, G. tricincta, Penicillium expansum, Pestalotiopsis sydowiana, Phoma glomerata, Ph. medicaginis, Pleurostomophora richardsiae and others occurred in large numbers. The dynamics of leaf colonization by fungi causing necrosis increased during the vegetation period. In November 2012, over $60 \%$ more of the fungous colonies were isolated in comparison with the number isolated in July. The most infected plants grew nearer to the acoustic screen. Kacper and Polish Spirit were the most infected cultivars, whereas Etoile Violette and Maidwell Hall were the least infected. The occurrence of fungi resulted in the considerable worsening of the decorative values of the plants.

Key words: clematis; leaves; fungi; necrosis; decorative values

\section{Streszczenie}

W dwuletnich badaniach (2011-2012) prowadzonych na terenie miasta Krakowa stwierdzono zamieranie liści powojnika. Na zamierających liściach z symptomami nekrozy, bytowało 46 gatunków grzybów, wśród których dominowały Alternaria alternata i Epicoccum nigrum. Licznie wystąpiły: Arthinium phaeospermum, Boeremia exigua, Botrytis cinerea, Chaetomium globosum, Cladosporium cladosporioides, Fusarium oxysporum, Gibberella baccata, G. tricincta, Penicillium expansum, Pestalotiopsis sydowiana, Phoma glomerata, Ph. medicaginis, Pleurostomophora richardsiae i inne. Dynamika zasiedlania liści przez grzyby powodujące nekrozę rosła w okresie wegetacyjnym. W listopadzie 2012 roku z porażonych liści wyodrębniono o ponad 60\% więcej kolonii grzybów niż w lipcu. Najsilniej porażone były powojniki rosnące przy ekranie akustycznym. Największemu porażeniu ulegały odmiany Kacper i Polish Spirit, a najmniejszemu Etoile Violette i Maidwell Hall. Grzyby bytujące na liściach powojnika w znacznym stopniu obniżyły walory dekoracyjne roślin.

Słowa kluczowe: powojnik; liście; grzyby; nekroza; walory dekoracyjne

Uniwersytet Rolniczy im. Hugona Kołłątaja w Krakowie

Katedra Ochrony Roślin

Al. 29 Listopada 54, 31-425 Kraków

m.kowalik@ogr.ur.krakow.pl 


\section{Wstęp / Introduction}

Powojniki są wszechstronnymi roślinami, mającymi wiele zastosowań $\mathrm{z}$ racji bujnego wzrostu oraz bogactwa gatunków i odmian. Obecne w środowisku człowieka ożywiają ogrody, zdobią ściany domów, porastają elementy małej architektury, pną się po ogrodzeniach zasłaniając nieatrakcyjne miejsca. Pnącza te odgrywają ważną rolę w terenach miejskich, są coraz częściej sadzone przy ekranach akustycznych, gdzie wspomagają funkcje izolacyjną i dźwiękochłonną oraz pochłaniają zanieczyszczenia gazowe i pyłowe (Marczyński 2008, 2009; Chojnowska 2010; Trzaskowska 2010). W tych trudnych warunkach, walory dekoracyjne powojników obniżają czynniki chorobotwórcze powodujące zamieranie ich organów lub całych roślin (Łabanowski i wsp. 2000; Łabanowski i Wojdyła 2007; Jędrzejuk i wsp. 2013).

Celem badań prowadzonych na terenie Krakowa było określenie przyczyn zamierania liści powojników.

\section{Materiały i metody / Materials and methods}

Materiałem do badań były rośliny powojnika z kolekcji Ogrodu Botanicznego Uniwersytetu Jagiellońskiego, terenu przy Akademii Wychowania Fizycznego (AWF) i kampusu Wydziału Ogrodniczego Uniwersytetu Rolniczego (UR). Na terenie kampusu UR badania prowadzono w kolekcji roślin ozdobnych i przy ekranie akustycznym przy ul. 29 Listopada. Badaniami określającymi zdrowotność pnaczy objęto w latach 2011-2012, 50 roślin powojnika reprezentujących 10 odmian. Do badań mykologicznych pobrano corocznie, w lipcu, wrześniu i listopadzie za- mierające liście z objawami nekrozy. Fragmenty tkanek liści (900 szt.) wyłożono na pożywkę PDA (Potato Dextrose Agar). Izolację i hodowlę kolonii grzybów przeprowadzono zgodnie ze standardowymi metodami stosowanymi w mykologii. Grzyby oznaczono do gatunku w oparciu o klucze mykologiczne: Guba (1961), Domsch i wsp. (1980), Sutton (1980), Sivanesan (1984), Ellis i Ellis (1987) i zweryfikowano według bazy Index Fungorum (2014).

\section{Wyniki i dyskusja / Results and discussion}

Przyczyną zamierania liści powojnika były choroby wywołane przez grzyby. Na roślinach rosnacych w kolekcjach Ogrodu Botanicznego Uniwersytetu Jagiellońskiego (UJ) i Wydziału Ogrodniczego Uniwersytetu Rolniczego (UR), na terenie Akademii Wychowania Fizycznego (AWF) oraz przy ekranie akustycznym zdiagnozowano (w obydwu latach badań) występującą w niewielkim nasileniu askochytozę powojnika Ascochyta clematidina. Na blaszkach liściowych widoczne były małe, okrągłe, szare plamy; z czasem liście żółkły, więdły i zamierały. Najsilniejsze porażenie stwierdzono na odmianie Lambton Park w kolekcji roślin UR i przy ekranie akustycznym, ale nie doszło do zamierania całych liści i pędów, o czym piszą Łabanowski i wsp. (2000). We wrześniu 2011 roku, podczas deszczowej pogody widoczne były objawy szarej pleśni Botrytis cinerea na odmianach Aureolin i Lambton Park, również w kolekcji UR. Łabanowski i Wojdyła (2007) piszą, że patogen ten poraża większość pnączy, ale szczególnie niebezpieczny jest dla powojników okrywowych.

Tabela 1. Grzyby wyizolowane z porażonych liści powojnika (Clematis L.)

Table 1. Fungi isolated from infected leaves of clematis (Clematis L.)

\begin{tabular}{|c|c|c|c|c|c|c|c|c|}
\hline \multirow[b]{3}{*}{ Grzyb - Fungus } & \multicolumn{6}{|c|}{$\begin{array}{l}\text { Frekwencja grzybów na liściach w latach: } \\
\text { Frequency of fungi on leaves in years: }\end{array}$} & \multirow{3}{*}{$\begin{array}{l}\text { Ogółem } \\
\text { Total }\end{array}$} & \multirow{3}{*}{$\begin{array}{c}\% \text { udział } \\
\text { Percentage } \\
{[\%]}\end{array}$} \\
\hline & \multicolumn{3}{|c|}{2011} & \multicolumn{3}{|c|}{2012} & & \\
\hline & $\stackrel{0}{\Xi} \triangleq$ & 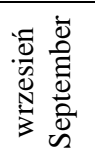 & 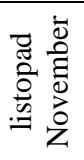 & $\stackrel{\mathscr{\varrho}}{:} \stackrel{2}{\Xi}$ & 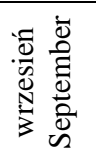 & 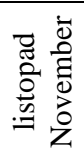 & & \\
\hline 1 & 2 & 3 & 4 & 5 & 6 & 7 & 8 & 9 \\
\hline \multicolumn{9}{|c|}{$\begin{array}{l}\text { Dominanty o liczebności }>5 \% \text { całości zbiorowiska } \\
\text { Dominant on the size of }>5 \% \text { of the total community }\end{array}$} \\
\hline Alternaria alternata (Fr.) Keissl. & 52 & 95 & 80 & 44 & 85 & 109 & 465 & 60,39 \\
\hline Epicoccum nigrum Link & 2 & 12 & 13 & & & 14 & 41 & 5,32 \\
\hline \multicolumn{9}{|c|}{$\begin{array}{l}\text { Influenty o liczebności } 1-5 \% \text { całości zbiorowiska } \\
\text { Influenty about } 1-5 \% \text { of the total number of communities }\end{array}$} \\
\hline Botrytis cinerea Pers. & 3 & 9 & 8 & & & & 20 & 4,03 \\
\hline Phoma medicaginis Malbr. \& Roum. & 17 & 7 & 6 & & & 1 & 31 & 2,60 \\
\hline $\begin{array}{l}\text { Pleurostomophora richardsiae (Nannf.) } \\
\text { L. Mostert, W. Gams \&Verkley }\end{array}$ & & & & 1 & 10 & 3 & 14 & 1,82 \\
\hline $\begin{array}{l}\text { Boeremia exigua (Desm.) Aveskamp, Gruyter } \\
\text { \& Verkley }\end{array}$ & 6 & & & 5 & & 2 & 13 & 1,69 \\
\hline $\begin{array}{l}\text { Gibberella tricincta El-Gholl, McRitchie, Schault. } \\
\text { \& Ridings }\end{array}$ & & 9 & 4 & & & & 13 & 1,69 \\
\hline
\end{tabular}




\begin{tabular}{l|c|c|c|c|c|c|c|c}
\hline \multicolumn{1}{c|}{1} & 2 & 3 & 4 & 5 & 6 & 7 & 8 & 9 \\
\hline Fusarium oxysporum Schlecht. & & & & 5 & 8 & & 13 & 1,69 \\
\hline Pestalotiopsis sydowiana (Bres) B. Sutton & & & & 8 & & 5 & 13 & 1,69 \\
\hline Penicillium expansum Link & & & 5 & 6 & & & 11 & 1,42 \\
\hline Arthrinium phaeospermum (Corda) M.B. Ellis & 3 & 1 & 6 & & & & 10 & 1,30 \\
\hline Chaetomium globosum Kunze & 2 & & & & 8 & & 10 & 1,30 \\
\hline $\begin{array}{l}\text { Cladosporium cladosporioides (Fresen.) G.A. } \\
\text { de Vries }\end{array}$ & & 1 & 2 & 1 & & 6 & 10 & 1,30 \\
\hline Gibberella baccata (Wallr.) Sacc. & & & 6 & & & 3 & 9 & 1,17 \\
\hline Phoma glomerata (Corda) Wollenw. \& Hochapfel & 1 & & & 4 & 4 & & 9 & 1,17 \\
\hline Penicillium javanicum J.F.H. Beyma & 1 & & & 7 & & & 8 & 1,04 \\
\hline Phoma leveillei Boerema \& G.J. Bollen & 1 & 7 & & & & & 8 & 1,04 \\
\hline
\end{tabular}

Akcesoryczne o liczebności $<1 \%$ całości zbiorowiska

Akcesoryczne about the size of $<1 \%$ of the total community

\begin{tabular}{|c|c|c|c|c|c|c|c|c|}
\hline Aspergillus versicolor (Vuill.) Tirab. & & & & 6 & 1 & & 7 & 0,91 \\
\hline $\begin{array}{l}\text { Paraphoma chrysanthemicola (Hollós) Gruyter, } \\
\text { Aveskamp \& Verkley }\end{array}$ & 2 & & & & 5 & & 7 & 0,91 \\
\hline Pestalotiopsis versicolor (Speg.) Steyaert & & 7 & & & & & 7 & 0,91 \\
\hline Rhizopus arrhizus A. Fisch & 6 & & & & & & 6 & 0,78 \\
\hline Cladosporium sphaerospermum Penz. & 1 & & 2 & & & 2 & 5 & 0,65 \\
\hline Phialophora cyclaminis J.F.H. Beyma & & & 4 & & & 1 & 5 & 0,65 \\
\hline $\begin{array}{l}\text { Boeremia hedericola (Durieu \& Mont.) Aveskamp, } \\
\text { Gruyter \& Verkley }\end{array}$ & 1 & & & & 3 & & 4 & 0,52 \\
\hline $\begin{array}{l}\text { Ilyonectria radicicola (Gerlach \& L. Nilson) } \\
\text { P. Chaverri \& Salgado }\end{array}$ & & 4 & & & & & 4 & 0,52 \\
\hline Penicillium jensenii K.M. Zalessky & & & & 2 & & 1 & 3 & 0,39 \\
\hline $\begin{array}{l}\text { Cadophora malorum (Kidd \& Beaumont) } \\
\text { W. Gams }\end{array}$ & & & & & 2 & & 2 & 0,26 \\
\hline Mucor hiemalis Wehmer & 2 & & & & & & 2 & 0,26 \\
\hline $\begin{array}{l}\text { Pyrenochaeta cava (Schulzer) Gruyter, Aveskamp \& } \\
\text { Verkley }\end{array}$ & & 2 & & & & & 2 & 0,26 \\
\hline $\begin{array}{l}\text { Thelonectria lucida ((Höhn.) P. Chaverri } \\
\& \text { C. Salgado }\end{array}$ & & 2 & & & & & 2 & 0,26 \\
\hline Cadophora fastigiata Lagerb. \& Melin & & & & & & 1 & 1 & 0,13 \\
\hline $\begin{array}{l}\text { Davidiella macrocarpa } \text { Crous, K. Schub. } \\
\text { \& U. Braun }\end{array}$ & 1 & & & & & & 1 & 0,13 \\
\hline Fusarium sporotrichioides Sherb. & 1 & & & & & & 1 & 0,13 \\
\hline Isaria farinosa (Holmsk.) Fr. & & & 1 & & & & 1 & 0,13 \\
\hline Khuskia oryzae H.J. Hadson & & 1 & & & & & 1 & 0,13 \\
\hline Mortierella alpina Peyronel & & & & 1 & & & 1 & 0,13 \\
\hline Papulaspora immersa Hotson & & & 1 & & & & 1 & 0,13 \\
\hline Phialophora cinerescens (Wollenw.) J.F.H. Beyma & & & & 1 & & & 1 & 0,13 \\
\hline P. verrucosa Medlar & 1 & & & & & & 1 & 0,13 \\
\hline Phoma putaminum Speg. & & & & 1 & & & 1 & 0,13 \\
\hline Rhizopus stolonifer (Ehrenb.) Vuill. & & 1 & & & & & 1 & 0,13 \\
\hline Tetracoccosporium paxianum Szabó & & & 1 & & & & 1 & 0,13 \\
\hline Trichoderma polysporum (Link) Rifai & 1 & & & & & & 1 & 0,13 \\
\hline T. viride Pers. & 1 & & & & & & 1 & 0,13 \\
\hline Trichothecium roseum (Pers.) Link & & 1 & & & & & 1 & 0,13 \\
\hline Umbelopsis isabellina (Oudem.) W. Gams & & & 1 & & & & 1 & 0,13 \\
\hline Ogółem - Total & 105 & 159 & 140 & 92 & 126 & 148 & 770 & 100,00 \\
\hline
\end{tabular}


Symptomem chorób, widocznym na wszystkich badanych roślinach, była nekroza liści. Oceniając nasilenie nekroz, stwierdzono, że na większości roślin powojnika rosnących przy ekranie akustycznym i w kolekcjach, już w maju widoczna była nekroza obejmująca do $50 \%$ powierzchni blaszki liściowej (postępująca od wierzchołka i brzegów liścia), a z czasem opanowująca całe blaszki i powodująca zamieranie liści. Nekroza liści najszybciej postępowała na powojnikach Polish Spirit, rosnących przy ekranie akustycznym, osiągając w listopadzie prawie 100\% porażenie blaszek liściowych. Objawy nekrozy na powojnikach Polish Spirit przy AWF widoczne były w niewielkim nasileniu (5-10\%), dopiero w październiku 2012 roku.

$\mathrm{Na}$ tak silne porażenie roślin przy ekranie akustycznym, miały wpływ niekorzystne warunki siedliska (ograniczona przestrzeń rozwoju korzeni, słabo przepuszczalne podłoże, silne nasłonecznienie, wysoka temperatura w sąsiedztwie ekranu), co skutkowało obniżoną odpornością na czynniki chorobotwórcze. Trudne warunki dla wzrostu pnączy panujące w strefach zurbanizowanych opisują Borowski i Latocha (2006) wskazując jako najbardziej niekorzystne stanowiska przy jezdniach oraz ekranach akustycznych. Lepsze warunki do wzrostu i rozwoju powojników panowały w kolekcjach Ogrodu Botanicznego UJ i Wydziału Ogrodniczego UR. Rośliny towarzyszące powojnikom tworzyły korzystny mikroklimat, osłaniając je przed nadmiernym nasłonecznieniem, przegrzaniem i zanieczyszczeniami atmosferycznymi. Najmniej symptomów chorób (przede wszystkim nekroz) widoczne było na odmianach Etoile Violette i Maidwell Hall.

W badaniach mikologicznych określających sprawców nekroz widocznych na porażonych powojnikach, ze znekrotyzowanych blaszek liściowych wyizolowano 770 kolonii grzybów, należących do 46 gatunków (tab. 1).

Grzybem dominującym był nekrotrof A. alternata, stanowiący ponad $60 \%$ wyizolowanych kolonii. A. alternata został wyodrębniony $\mathrm{z}$ roślin wszystkich odmian powojnika, najwięcej kolonii wyizolowano $\mathrm{z}$ odmian Polish Spirit i Kacper. Polifag ten wywołuje alternariozę na powojniku i innych roślinach ozdobnych (Łabanowski i wsp. 2000; Marczyński 2008; Kowalik i Bigaj 2012).

Do grzybów dominujących w zbiorowisku zaliczono także E. nigrum; grzyb ten licznie zasiedlał fyllosferę powojnika, powodując nekrozę. Wyizolowanie z zamierających liści polifaga $B$. cinerea jest potwierdzeniem występowania szarej pleśni na powojniku.

$\mathrm{Z}$ porażonych, zamierających liści wyizolowano znaczną liczbę kolonii: A. phaeospermum, B, exigua, Ch. Globosum, C. cladosporioides, $F$. oxysporum, $G$. baccata, G. tricincta, P. expansum, P. sydowiana, Ph. glomerata, $P h$. medicaginis, $P$. richardsiae i inne. Obecność na zamierających liściach powojnika kolonii grzybów rodzaju Fusarium (Gibberella), Ilyonectria (Cylindrocarpon), Phoma (Boeremia, Paraphoma), Pleurostomophora (Phialophora) świadczy o rozszerzeniu zakresu żywicieli i różnorodności bytujących na nich grzybów (Domsch i wsp. 1980; Łabanowski i wsp. 2000; Łabanowski i Wojdyła 2007; Jędrzejuk i wsp. 2013).

Toksyny produkowane przez A. alternata (tenotoksyna i brefeldyna A) i inne produkowane przez grzyby rodzajów: Aspergillus, Fusarium, Gibberella, Penicillium mogą zakłócać wiele procesów biochemicznych, nasilać objawy chorób, prowadzić do zmniejszenia powierzchni asymilacyjnej liścia (Chełkowski 2013) i defoliacji (Kowalik i Bigaj 2012).

Dynamika zasiedlania liści przez grzyby powodujące nekrozę rosła w okresie wegetacyjnym. W listopadzie 2012 roku z porażonych liści wyodrębniono o ponad $60 \%$ więcej kolonii grzybów niż w lipcu.

$\mathrm{Na}$ liściach powojnika bytowały też gatunki sporadyczne, jak: C. fastigiata, D. macrocarpa, F. sporotrichioides, I. farinosa, K. oryzae, M. alpina, P. immersa, $P h$. cinerescens, Ph. verrucosa, Ph. putaminum, $R$. stolonifer, T. paxianum, T. polysporum, T. viride, T. roseum i U. isabellina. Grzyby te, w większości zaliczane do saprotrofów, wyizolowano ze znekrotyzowanych tkanek jako pojedyncze kolonie.

Nie wyizolowano patogenów wywołujących plamistości liści, jak: C. gloeosporioides, P. clematidis, R. clematidis, S. clematidis (Łabanowski i wsp. 2000; Łabanowski i Wojdyła 2007), ani podawanych w literaturze jako bytujące na roślinach powojnika: L. haematites, $P$. vitalbe, B. vitalbae, E. fusispora, Ph. demissa, $R$. unicaudata i Ph. lingam (Sutton 1980; Sivanesan 1984; Ellis i Ellis 1987).

Grzyby zasiedlające powojniki powodowały zamieranie liści, co $\mathrm{w}$ znacznym stopniu obniżyło walory dekoracyjne tych roślin.

\section{Wnioski / Conclusions}

1. Zamieranie liści powojnika Clematis L. powodował kompleks grzybów strzępkowych, a wyniki analizy mykologicznej potwierdziły różnorodność grzybów bytujących w fyllosferze roślin.

2. Wśród sprawców zamierania liści powojnika dominującą rolę odegrał nekrotrof A. alternata.

3. Grzyby bytujące na liściach powojnika w znacznym stopniu obniżyły walory dekoracyjne roślin.

4. W miastach, szczególnie przy ekranach akustycznych, należy unikać sadzenia odmian Kacper i Polish Spirit, z uwagi na ich wysoką podatność na porażenie przez grzyby.

\section{Literatura / References}

Borowski J., Łatocha P. 2006. Dobór drzew i krzewów do warunków przyulicznych Warszawy i miast centralnej Polski. Rocz. Dendrol. 54: 83-92. 
Chełkowski J. 2013. Mikotoksyny, grzyby toksynotwórcze i mikotoksykozy. www.cropnet.pl [dostęp: 07.05.2013].

Chojnowska E. 2010. Powojniki. Działkowiec, Warszawa, 72 ss.

Domsch K.H., Gams W., Anderson T.H. 1980. Compendium of Soil Fungi. Acad. Press, London, New York, Toronto, Sydney, San Francisco, 859 pp.

Ellis M.B., Ellis J.P. 1987. Microfungi on Land Plants. An Identification Handbook. Croom. Helm, London, 818 pp.

Guba E.F. 1961. Monograph of Monochaetia and Pestalotia. Harvard University Press. Cambridge, Massachusetts, 256 pp.

Index Fungorum. 2014. www.indexfungorum.org [dostęp: 08.01.2014].

Jędrzejuk A., Rochala J., Rabiza-Świder J. 2013. Occurrence of blockage in cut stems of Clematis L. Acta Agrobot. 66 (1): 3-8.

Kowalik M., Bigaj K. 2012. Przyczyny plamistości liści ligustru pospolitego (Ligustrum vulgare L.). [Causal agents of leaf spot disease of common privet (Ligustrum vulgare L.)]. Prog. Plant Prot./ Post. Ochr. Roślin 52 (1): 69-72.

Łabanowski G., Orlikowski L., Soika G., Wojdyła A. 2000. Ochrona ozdobnych pnączy. Plantpress, Kraków: 36-40.

Łabanowski G., Wojdyła A. 2007. Ochrona pnączy. Działkowiec, Warszawa: 58-61.

Marczyński Sz. 2008. Clematis i inne pnącza ogrodowe. Oficyna Wydawnicza Multico, Warszawa: 112-169.

Marczyński Sz. 2009. Pnącza w zieleni miejskiej i przy drogach. Wydawnictwo Clematis, Sz. Marczyński, W. Piotrowski sp. j., Szkółka Pojemnikowa, Pruszków, 34 ss.

Sivanesan A. 1984. The Bitunicate Ascomycetes and their Anamorphs. J. Cramer, Vaduz, 700 pp.

Sutton B.C. 1980. The Coelomycetes. Fungi Imperfecti with Pycnidia, Acervuli and Stromata. Com. Mycol. Inst. Kew, Surrey, England, $696 \mathrm{pp}$.

Trzaskowska E. 2010. Wykorzystanie roślin w projektowaniu architektonicznym (pnącza, ogrody wertykalne). Teka Komisji Architektury, Urbanistyki i Studiów Krajobrazowych OL PAN, Lublin: 110-121. 